\title{
EXPLORING THE QUALITY OF LIFE OF PEOPLE IN NORTH EASTERN AND SOUTHERN THAILAND
}

\author{
(Accepted 9 August 2005)
}

\begin{abstract}
The assumption that development brings not only material prosperity but also a better overall quality of life lies at the heart of the development project. Against this, critics assert that development can undermine social cohesion and threaten cultural integrity. Rarely, however, is the impact of development on wellbeing rigourously analysed using empirical data. This is what the Wellbeing in Developing Countries Group at the University of Bath aims to do drawing on fieldwork carried out in four developing countries, which addresses the themes of resources, needs, agency and structure, and subjective Quality of life (QoL). The first phase of the QoL research in Thailand aimed to explore the categories and components of quality of life for people from different backgrounds and locations with the aim of developing methods for QoL assessment in the third phase of the WeD QoL research. The study presents data obtained from rural and peri-urban sites in Southern and Northeastern Thailand (two villages in Songkhla and three in Khon Kaen, Mukdaharn, and Roi-et). Participants were divided into six groups by gender and age, and were divided again by religion (Buddhist and Muslim) and wealth status in the South. Data collection was conducted between October and December 2004 using focus group discussions, semi-structured interviews, and the Person Generated Index. Content analysis was used for data analysis. The use of a qualitative approach enabled the gathering of empirical data that reflects the sources of difficulty and happiness in the lives of participants. Respondents identified 26 aspects to their quality of life, including family relations, health and longevity, income and having money, jobs, housing, education, debt, and so on. The results reveal clear similarities and differences in the role of traditions, religious beliefs, and values in the lives of people living in remote rural or peri-urban areas in Northeastern and Southern Thailand. These results, together with the findings from Peru, Ethiopia, and Bangladesh, will inform the rest of the WeD research and be used to develop measures to assess the quality of life of people living in developing countries.
\end{abstract}

KEY WORDS: developing countries, Person Generated Index, poverty alleviation, qualitative methods, quality of life assessment, Thailand, well-being 


\section{BACKGROUND TO THE STUDY}

Development in Thailand has historically focused on the capital city, Bangkok, however, the saying "Bangkok is Thailand" reflects the uneven development between the centre and the other regions of Thailand. For example, $40 \%$ of the Thai economy is located in Bangkok but only $9.5 \%$ of the population, and the per capita income of people in Bangkok is nine times greater than the national average (National Economic and Social Development Board [NESDB], 2002). This is especially true of NE Thailand, which despite housing a third of the population has the lowest per capita income and, like the South of Thailand, comparatively poor access to services.

The NESDB (2004) reported that while the life expectancy of the Thai people has been improving (currently 5.9 years higher than the global average for men and 6.9 years higher for women), their physical and psychological well-being has deteriorated. This is partly due to the increasing incidence of 'diseases of affluence', for example, obesity, diabetes, non-infectious diseases such as heart disease and cancer, and road traffic accidents. The situation has been partially compensated for by an increase in the national health insurance coverage from $69 \%$ in 1996 to $95 \%$ in 2002 , due to the ' 30 Baht Health Scheme'. However, there are still some doubts about the quality and standard of services provided, as well as the likely costs to the government.

Qualitative studies have also recorded considerable suffering and anxiety among the elderly who don't have access to national welfare. Aging parents worry that they will be left alone in the house because all their family members have become economic migrants. Widows and single mothers are also vulnerable and there is other evidence that poor and marginalised people in Thai society are not protected and served (for example, they have not yet received full distribution of national welfare, despite the Thai government's expressed desire to improve the quality of life (QoL) of its people). Many Thai people have difficulties accessing government agencies and their services are often outdated or of dubious quality. It is calculated that within 10 years, the majority of Thai people will be either old or very old (NESDB, 2002). However, to date no plan has been put forward to deal with the potential problems presented by this demographic change. The current Social Security System 
does not adequately ensure the well-being of the people. Therefore, it is a considerable challenge for the Thai government to find a way to improve its national economic and social development plans, including labour protection, social welfare, consumer protection, accident insurance, a social security system to care for the poor and the marginalised, and control of crime, violence, and drug abuse.

Gross National Income and Economic Growth Rate have been used as indicators of development success since the first National Economic and Social Development plan (Thailand is now on its 9th plan). Before the appearance of early signs of the economic collapse in 1996, Thailand seemed to have successfully met all the indicators of successful development. However, almost every Thai household had expenses in excess of their income and did not have any savings. The environment had also deteriorated with the loss of woodlands and loamy soils for agriculture. Many young adults had become economic migrants; consequently most rural communities were comprised of children and old people who survived on small remittances. After the economic collapse, these people faced even more hardship.

The economic collapse underlined the inadequacy of economic indicators as measures of the success of development, however, fortunately there has been a parallel movement within Thailand adapting and developing locally appropriate 'social indicators' and measures of QoL (reviewed in Ayawut and Phitakham, 2004). For example, in 1986 the Ministry of Public Health produced indicators of the QoL of the Thai people called the "Eight Fundamental Needs." These comprised good food, housing, (subjective) well-being, plenty of produce, birth spacing, community collaboration, and morality. Thirty-two indicators were used to determine the quality of people's lives.

In 1990, the United Nations developed indicators of QoL specifically for use in Asian and Pacific countries. These were based on the "New Social Indicators" (UNDP, 1989) and included subjective and objective data about health, safety and the environment, economic stability, family, work, and educational life, community involvement, and cultural activity.

Pongsapitch et al. (2000) took a more focused approach by developing a tool specifically to assess the QoL of Thai people. This 
was done through participatory action research with local people, which used a qualitative approach to obtain data from 'key informants' with different backgrounds at the community level. The first phase of the study identified eight indicators of QoL, namely good infrastructure and environment, the economy, public health and wellness, information and learning, academic and human resources, culture and spirit, public society, security, rights and freedom, and family and community. In the same year, with the collaboration of people in NE Thailand, Thamrongwarangune et al. (2000) developed a measure to assess the QoL of people in the NE using a sample of 200 people from four provinces. Eight indexes measuring happiness in life were obtained: life security, good physical and psychological health, good relationships within the family, strong community, good environment, freedom, pride, and living together virtuously (ethically).

Other researchers exploring meanings of happiness that go beyond the quantifiable have drawn on the rich spiritual traditions active within Thailand. There is a teaching in Buddhism that happiness is the long lasting harmony of mind and heart. The ultimate happiness is the liberation from suffering (or the 'unsatisfactoriness' of worldly things) [Dukkha]. This definition of happiness differs from pleasure, which is essentially transient and refers to feelings of enjoyment from seeing, smelling, tasting, hearing, and touching (Dalai Lama and Culter, 1999). The Quran also states that happiness arises when a Muslim is touched by Allah and practices the 'Five Pillars' of Islam (belief in Allah and his prophet Mohammed, daily prayers, giving alms, fasting, and pilgrimage to Mecca).

The research of the Wellbeing in Developing Countries Group at the University of Bath (WeD) similarly attempts to understand how people experience well-being through "the analysis not of subjective components of well-being, but the subjective, socially and culturally constructed experience of well-being as a whole" (White and Petitt 2004, p 8-9 ). A complete picture therefore comprises not only people's objective endowments, but also the inter-subjective in the form of their social interactions, their subjective perceptions, and the ethical or moral aspects of well-being, reflected in what people value. The 'being' of well-being helps us by drawing our attention to states of mind and subjective perceptions, as well as 'state of body' and material endowments. 


\section{THE WeD RESEARCH PROGRAMME}

The WeD approach to QoL is based on the assumption that people reflect on the quality of their experiences to a greater or lesser degree, according to their cultural context. This reflection is influenced by the interplay of biological, social, and psychological processes, for example, the fit between people's goals and the extent to which they feel they can or have achieved them (related to perceived resource availability), historically and socially contextualised experiences and expectations, immediate environment and mood, and personality.

The goal of the WeD QoL research is to produce a methodology that creates a space for self-evaluation, where people can tell us what they value, what they have experienced, and how satisfied they are with what they have, and what they can do and be. This enquiry has been divided into three phases, an initial exploratory phase using participatory and ethnographic techniques to identify the categories and components of QoL for different individuals in different locations; a second conceptual phase, which reviews the data from the first phase on conceptions of QoL and the best methods to explore them, and attempts to integrate them with the QoL, Health-related QoL, Subjective Well-being, and psychology literatures; and a third methodological phase, involving the development of a specific measure of QoL (WeD-QoL, see Camfield, 2004).

The first phase of the QoL research began with a workshop in Bath exploring the components of QoL for each of the four WeD countries, followed by workshops with QoL 'experts' (e.g. NGO workers) in the countries (Skevington, 2003). The Person Generated Index (PGI), an individualised QoL measure, which asks people to nominate aspects of life that contribute to their well-being and rate them according to how important they are and how satisfied they are with them (Ruta et al 1994, 1998), was also piloted in three of the four countries (e.g. Bevan et al., 2003). This took place alongside Community Profiling, which asked questions relating to quality of life and well-being (see particularly the Well-being and Ill-being Dynamics in Ethiopia study, WIDE 2), and the Resources and Needs Questionnaire, which used both 'consumption adequacy' questions to establish people's satisfaction with areas like food and healthcare, and a 
standard 'global' happiness question (see World Database of Happiness, http://www2.eur.nl/fsw/research/happiness/hap_quer/).

The more intensive part of the exploratory fieldwork involved semistructured interviews, focus group discussions, and the piloting of other measures, such as the Satisfaction with Life Scale or SWLS (Diener et al. 1985). This took place in rural, peri-urban, and urban sites in Bangladesh, Ethiopia, Thailand and Peru. The average sample size for the countries was 360 (range 314-419) and age and gender were used as the key 'breaking variables', followed by religion or ethnicity.

This paper comes from the work of WeD in Thailand, which used open-ended qualitative questions with individuals and groups to explore the areas of their lives that people felt were most important. This was supplemented by community profiling (helping the team to understand the socio-cultural background of the respondents) and administration of the Person Generated Index (PGI). Proposed themes of QoL were written in Thai and then translated into English, and the reports of the focus groups and semi-structured interviews were also translated for more detailed analysis.

\section{METHODS, SITE SELECTION, AND SAMPLING}

The main methodologies used with individuals were focus group discussions and semi-structured interviews, including administration of the PGI, as described below. The preliminary list of focus group and interview questions were discussed by the research team and translation of the questions into Thai was completed by 'native speakers' who were also fluent in English. The questions were then piloted in two peri-urban locations in the North East and South and any necessary amendments made (for example, checking that the specific words used to describe well-being would be equally comprehensible to Southern Muslims).

\section{Focus Group Discussions (FGDs)}

Focus group discussions $(n=6)$ were conducted with men and women aged 18-30, 31-60, and over 60 in the North Eastern and Southern sites (three extra groups were conducted in the South to accommodate the presence of Muslims and Buddhists). A balance 
needed to be achieved between having a sample that was sufficiently diverse to represent the range of opinions within the community, but also homogenous enough to facilitate free discussion. Background information on the participants was collected including name, age, education, occupation.

The focus group discussions were organised by teams of three research assistants from Khon Kaen and Songkhla universities who took turns to act as moderator, note-taker, and observer. The observers were responsible for describing the atmosphere of the focus group, e.g. the mood of the participants, where they were seated, and how they related to each other and the moderator.

\section{Semi-Structured Interviews (SSIs)}

The semi-structured interviews were approximately 45-60 minutes in length and took place either in people's homes or 'neutral' public spaces like community centres. The interviewer was usually the same gender as the respondent to increase the reliability of the responses. Background information was also collected, including the identification code from the Resources and Needs Questionnaire (RANQ) so their responses could be matched to other WeD data, and other observations were made such as the person's health, condition of their home, etc. Interviewers were also asked to note any observations relating to the respondent's mood, tone, facial expression, and body language.

Respondents were then asked nine open ended questions to get a sense of the characteristics of people who were perceived as living well or badly, and their personal experiences of well-being and ill-being (for example, the 'happiest' and 'unhappiest' times in their lives). Although interviewers used a common interview schedule (used in the other WeD countries), they made slight modifications where necessary (e.g. changing 'fears' to 'concerns' in question 8; see section 'Summary of results'). Interviewers were encouraged to probe further if people made interesting responses and allow them to express their ideas without interruption (Field and Morse, 1985).

\section{The Person Generated Index (PGI)}

The semi-structured interviews also used the PGI, which is an 'individualised QoL measure' that was developed by Ruta et al in 1994. 
and revised in 1998 to make it less health-focused. The PGI is a brief three-step measure. The individuals nominate up to five areas that they consider important to their lives (for example, family, house), and score these out of seven (0-6) to indicate their level of satisfaction (the higher the score, the higher their satisfaction level). They then 'spend' ten points across the areas to illustrate their relative importance and a final score is calculated to represent the shortfall between people's desired and actual achievement in these areas.

\section{Sites}

In Figure 1 the researchers from the $\mathrm{WeD}$ Thailand chose five communities to participate in the QoL research - two from Southern Thailand Isan and three from the Northeast. Southern and Northeastern Thailand (Isan) have distinctive regional identities and are considered the most economically disadvantaged parts of Thailand (NESDB 2002), albeit that the South is visibly wealthier than the Northeast. Two of the sites are located in Songkhla province in the

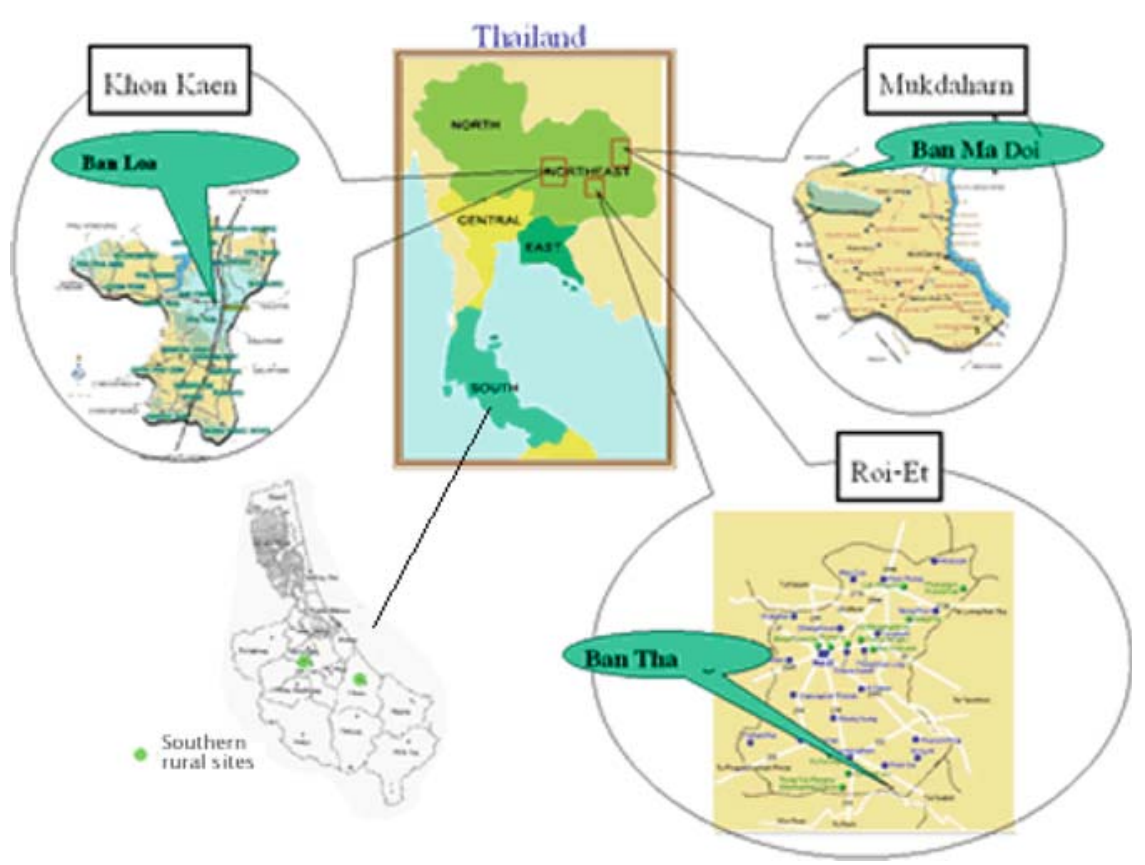

Figure 1. Map of sites. 
South, and one each from Khon Kaen, Mukdaharn, and Roi Et in the Northeast. The sites show interesting variations in size, landscape, religious composition, level of infrastructure, and distance from the provincial capital (see Table I). The sample within the sites was recruited from respondents to the RANQ (see Table II).

\section{FINDINGS FROM FOCUS GROUPS AND SEMI- STRUCTURED INTERVIEWS}

The following pages explore the thematic areas people described as having most influence on their QoL.

\section{Family Relationships}

Having good family relationships was important to all respondents young, old, male, female, urban, rural, Buddhist, and Muslim. Respondents also emphasised the importance of following the appropriate norms and codes of conducts, which governed behaviour towards different family members, for example, being respectful to your parents and attentive towards your children. However, some aspects of family relationships were specifically related to gender and age, for example, when asked, "What are the three best things about your life at the moment?" a 75 -year-old man living in a remote area responded "having children to look after me, having a wife to take care of me, and no fighting among the children". Other quotes mentioned the importance of having 'good' and well-mannered children, a responsible husband, and being able to care for their parents and be cared for in their turn.

During the semi-structured interviews, some of the women, especially poor women, had tears in their eyes when talking about the hardship in their families. An example of this was the life of a 63-year-old woman who had to raise two grandchildren, aged 3 and 8 years, after their parents passed away. Her husband died a year ago and though she had one son left, he worked in another province and had neither given her money nor visited her. Another woman who described herself as "living well" stated that she feared her children would leave her to live somewhere else and was worried that she 


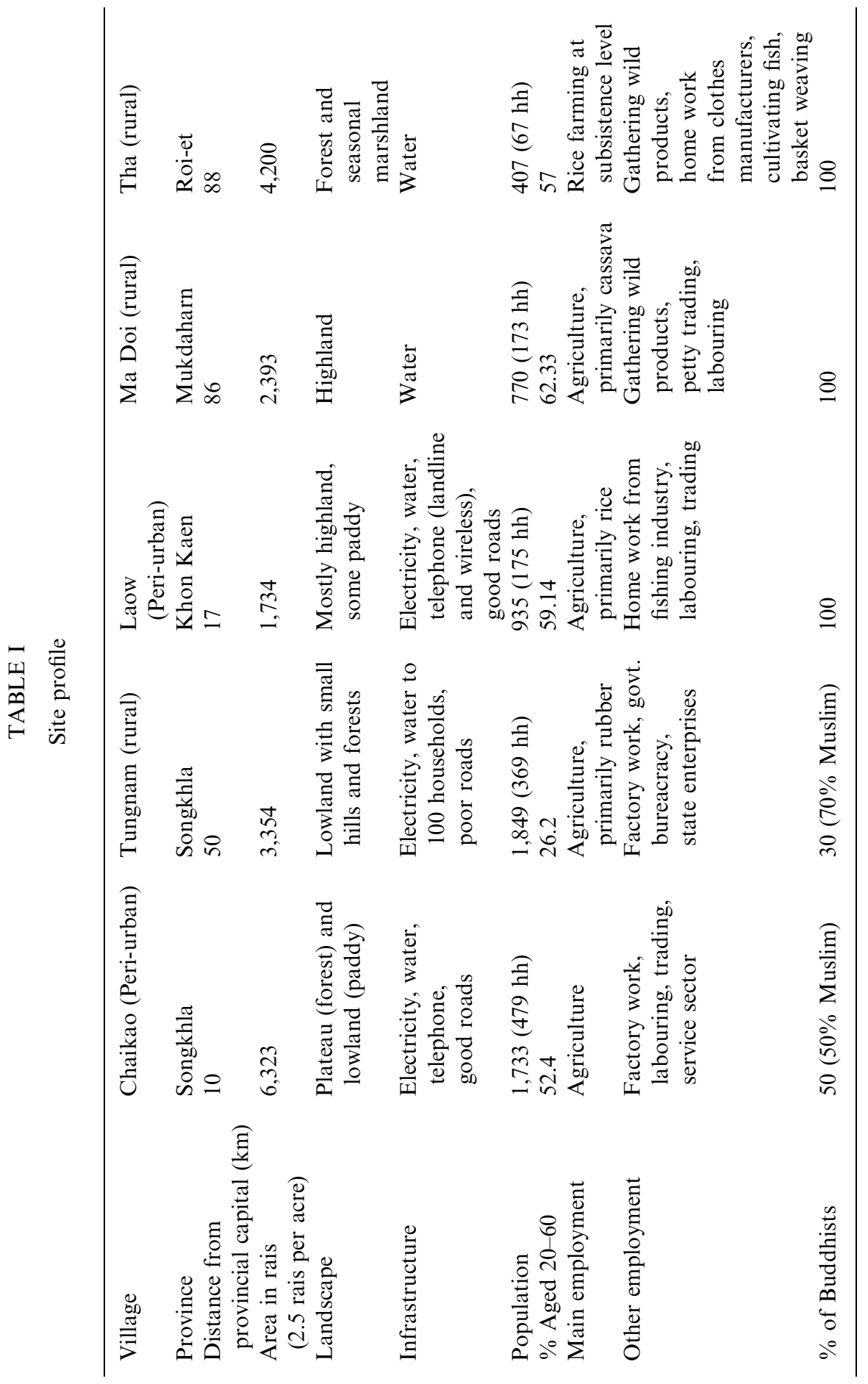


TABLE II

Sample

$\begin{array}{ll}\text { Provinces } & \text { Songkhla }(n=149), \\ & \text { Khon Kaen }(146), \text { Mukdaharn (63), } \\ & \text { and Roi-et (56) } \\ \text { No. of SSIs } & 102 \\ \text { No. of PGIs } & 102 \\ \text { No. of FGDs } & 36(n=212) \\ \text { Main sampling criteria } & \text { Young }(18-30), \text { middle-aged (31-60) } \\ & \text { and old (61 }+) \text { men and women; } \\ & \text { Buddhist and Muslim (South); } \\ & \text { rich and poor (South) }\end{array}$

would have to take care of both herself and her husband when they got sick.

Loyalty to the family was important for both Buddhist and Muslim women, hence the distress experienced by one 61-year-old woman who said,

This is the most difficult period for me. I have to be home alone. I feel lonely. The house is always very quiet when I get back from work in the rice field. All of my children are away to work. They don't send me any money. I have to work every day just to get by. What will happen when I cannot work any longer?

We observed that Southern Muslim woman of all ages rarely discussed their husbands during focus group discussions. Women who did talk about their husbands revealed feelings of resentment over their husband's role and responsibilities and tendency to put religious activities before their family's needs. In contrast, Buddhist women of all ages from Isan stated that they had suffered from their husband's drinking problems and lack of attention to making enough money for a decent living. This observation was supported by the data from the Ministry of Public Health (2004) concerning the amount of alcohol consumption by Thai males, which ranked No. 1 in Asia and No. 5 in the world (Press release, 2004). Husbands with drinking problems caused tremendous suffering to their wives and families, particularly within a Buddhist society where one of the five Buddhist 'commandments' forbids the consumption of alcohol.

One of the women from Isan told the interviewer that to solve this problem she would "Marry a foreign husband for a better life and 
wealth". Although marriages to 'foreign' men (Western Europe, North America, Japan, Taiwan, and Singapore) are not a new trend in Isan, due to the presence of American air force bases in Ubon and Udorn in the 1970s, they have only recently become a source of pride rather than stigma. To date, there are more than 15,284 Isan women married to foreign husbands, mainly of European and American origin (2,435 from Khon Kaen) (Thairath Daily News, 2004). According to the paper, women married foreign husbands to improve their own and their family's quality of life as husbands often gave money to their new families and helped their wives build a new house for their parents-in-law. Sometimes foreign son-in-laws settled down in Thailand and opened businesses such as restaurants, nightclubs, or convenience stores, or even became farmers. The foreign men also benefited because, according to the reporter, Thai women make ideal wives who take good care of their husbands, respect them, and treat them well.

Muslim men appeared keen to ensure the religious observance of their children, frequently stating during the interviews, "I hope my children will hold to the teachings of Allah". On the other hand, Buddhist men usually made general comments on their hopes for their children that did not relate to religion, for example, "I wish my children would be good and obedient to their parents". Obedience to parents seemed to be a key value in Isan society, which emerged in all interviews and discussions with people of all ages. However, parental obedience was comparatively rare in the data obtained from the South, which emphasised religious practice. Similarly, for Southern participants the ideal of "being good" also applied to interactions with other community members and society in general, while in Isan it was confined to parents, siblings, and families. This difference in focus also appeared in people's characterisation of the "ideal village/ town"; while people from Isan focused on community unity and receiving external help to improve infrastructure and services, Southern participants emphasised community cooperation in maintaining a good physical and moral environment, for example, engaging in religious activities, setting up strong trading cooperatives, and removing sources of temptation.

In contrast, the question about the 'best' or most admirable persons in the community" produced similar responses from the South and Isan as the majority of participants nominated people who 
studied religion or officiated at religious ceremonies (for example, monks or Imams). Other admirable people were traditional healers, fortune-tellers, community leaders and administrators, and local politicians. It should be noted that the majority of admirable people nominated were male, although there were women in these areas who had served their communities for years (for example, as traditional midwives).

\section{Health}

In this study, the category Health included statements about health, longevity, and the quality of the health services. There is a Thai saying that "Health is better than wealth". This was evident in the data from FGDs with women over 60 years old. One Southern respondent said, "It is okay not to have money. I want to be healthy". A 63-year-old religious scholar stated, "I am not young like I used to be. I cannot eat as I wish I could. I am on the downside of my life, just like the sunset". A 90-year-old Isan woman described her concern that,

I live long but I do not feel well at the moment. I do not have a good appetite. I feel fatigued. My body aches. I have insomnia. I cannot go to work in the rice field with my children. I want to live with my children for a long time but I fear that my children will leave me

Health was frequently nominated during semi-structured interviews and the PGI but was less frequently mentioned during focus group discussions. During focus group discussions, the statements about health referred to the need for the community to have good health services and health centres. The participants did not interpret health in terms of promoting community health, developing good health behaviours, or improving the environment. However, the data from FGDs of Southern males and females (aged 18-30 and 31-60 years, respectively) emphasised the public dimension of health to a greater extent than data from FGDs of Isan participants from the same age group. The Southern participants also suggested it would be good for their community to have public services to keep the environment free from litter, gambling, and drugs. They wanted their community to have a multi-purpose sports ground, but did not discuss other ways of building a healthy environment. 
The focus group data suggests that participants perceive health as a personal issue and people only concern themselves about their health when they have health problems. Therefore, health was usually not mentioned by young adults, although participants who were aged from 31 to 60 or over 60 years old regularly mentioned it. The older group described health as one of the reasons for 'unhappiness'. Both male and female participants who were sick indicated that illness cost a lot of money and stopped them from working. Common conditions were Kidney disorders, Diabetes Mellitus, Hypertension, Gout, and Arthritis. One 46-year-old woman who had chronic renal failure said,

I have had this kidney disease since the year 2000. I had to borrow money from the 'outside system' [i.e. informally] to pay for the medical bills. I have spent more than 100,000 Baht over the years. I don't know how I will ever have the money to pay them back. I feel miserable (FGD of women aged 31-59 from Northeastern Thailand)

Some participants feared that serious illness would rob their lives of joy and compromise their QoL. One 42-year-old woman from a remote area in Isan told the interviewer,

I used to work in the South of Thailand. Now I have a tumor of the spine. I also found out that I had vaginal bleeding so I went to a hospital to have it checked out. I am now waiting for the results of the test. I fear that I may have cervical cancer. I am worried sick because my family would suffer a lot if I get sick. I don't have money for transportation to the hospital. I can barely feed my family

Having a child or grandchild with a chronic disease also made parents and family members miserable. A 36-year-old mother who had a child with congenital heart disease and a bleeding disorder said in an interview,

I have been going back and forth between the hospital and home. I have to be extra careful about my costs of living. I cannot make enough money to pay for his medical bills. I feel too disheartened to work

All of the above focus on physical problems, but psychological problems were also a concern. Data from one FGD of males aged 18-30 years indicated that the participants suffered from several psychological or psychosocial problems including (1) conflict in their family, (2) abandonment of the elderly, and (3) stress resulting from economic and social problems. Family conflict was attributed to the irresponsibility of one of the spouses, usually a Buddhist male. Women from Muslim families revealed that their husbands gave time to religious and social activities rather than their families. Abandonment of the elderly was identified by old people left at 
home alone, sometimes with small children, while the rest of the family members went away to work. Widows also experienced stress after the death of their husbands as they often had to raise children or grandchildren on their own with no money or support. Staying married was very important for women in Isan as they believed that 'good' women would not divorce their husbands, no matter how bad or irresponsible they might be. Another source of stress was the financial difficulties described by many participants, for example, having no land or insecure tenure (a particular problem in the South).

\section{Income and Having Money}

Income was identified as important by all participants in the FGDs and SSIs, even those who were seen as wealthy by their peers because they had a rubber plantation, store, or plenty of rice fields. Participants reported that women who live well "have lots of money and don't have to work" (SSI with a Southern Buddhist woman aged 59 years). This was also true for men: "The greatest moment in my life was when I was 45 years old because I could make a lot of money" (SSI with a Southern Muslim man aged 74 years). Wealth was linked directly with well-being, illustrating the universality of the Thai saying that "money is work that makes happiness" or "money is God".

I think the most wealthy man is the one with most well-being. A wealthy man can buy anything he ever wants to eat (20-year-old man from Isan)

Even respondents perceived as wealthy experienced money problems due to a mismatch between expenditure and income ("all the money I make is spent as interest for my loan"). Middle aged participants reported the greatest financial problems as not having enough money caused difficulties in their families, required them to work very hard, meant they could not afford the necessary materials for their farms, and could not provide higher education or an inheritance for their children. It also affected young adults who said that not having enough money stopped them from buying things to make their lives easier or boost their self-esteem, and often caused them to drop out of school. Lack of money kept older participants working harder than they should have been at their age and deprived them of contact with 
their offspring who were supporting their families by working away from home and could not afford to return.

\section{$J o b$}

$J o b$ is defined here both as occupation and socioeconomic status, which is reflected in the fact that the new generation do not want to inherit the occupations of their ancestors. For example, one participant said, "I want to have an office job so that I don't have to be out in the sun throughout the day. A salary of 8,000 Baht should be enough for me" (18-year-old high school student in Isan). Participants perceived paid labour and working in the rice field as jobs that worsened their QoL. Some participants in a group of Isan women aged over 60 years stated, "Building a bridge, growing rice, plucking rice, harvesting rice, binding rice... People who have to work during old age are people who live badly". Jobs that provided a good QoL included jobs with authority and ones in air-conditioned offices. A 22-year-old Isan man who lived in a remote area stated,

The most regrettable thing in my life was having to stop studying after I finished secondary school. I wish I could have finished high school so that I could apply to study in a police academy. I want to be a policeman. It is a good job. People pay respect to policemen

Similarly, a 45-year-old Isan man who lived in a remote area said,

The happiest moment in my life was when my child was accepted to work in a company in Pathumthani Province. My child has got to work in an air-conditioned office, not in a rice field like me.

The above quote illustrates how people's jobs affect their QoL in many ways and can be a huge source of stress for the participants. When asked 'what are your current concerns?' one participant responded,

My greatest fear is getting fired from my job. If I lose my job, I will not be able to repay a debt for my mother and my girlfriend will leave me (26-year-old man from Isan who worked as a clerk in a department store)

Participants also wished for development interventions that would increase the economic well-being of local people by providing "supplementary occupations" (FGD of older women from a remote village in Isan).

There were different types of occupation in the South and Isan. For example, in Isan, people gathered wild produce to barter or 
sell. This was not an option for some Muslims who believe that a sacred spirit exists in every forest and therefore gathering wild produce is forbidden. This demonstrates the important role that beliefs can play in people's lives in terms of the way that they make a living.

\section{Housing and Food}

Housing and Food are defined by the Thai government as two of the four 'fundamental needs of human beings' (the others are clothing and medication); the quotes below demonstrate that having your own house is an important part of having a good life:

Good living means that you have to have a big comfortable house that has enough bedrooms for everyone in your family. The house should also have good ventilation so nobody in the family has any stress (FGD of males aged 31-60 years)

The best thing in life at this moment is that I am about to have my very own house. My house is being built and it is almost done. I will finally have my own house after spending years living with my parents (23-year-old man from Southern Thailand)

Other examples indicated that for that for people in Isan, having a roof to shield them from the sun and the rain was more important than the appearance of the house. However, the desire to have a big house was evident in responses from participants in peri-urban areas, or those who had lived or worked in cities.

Food becomes particularly important when there are special events to celebrate such as religious festivals or someone in the community winning the lottery. Villagers will kill their livestock or cattle and use them to feed the entire community for days. This tradition often leads to unhealthy eating behaviours, for example, every year many people from Isan need hospital treatment because they eat raw or halfcooked meat.

A 20-year-old man from Isan who repairs bikes for a living described his 'happiest moment' as

When I had a birthday party at which I got to drink and eat everything with my best friends. That was the moment that I will never forget

Responses from a FGD of older women revealed concerns about having clean food and water, "I wish our school was able to provide clean food and water for the students at lunch, especially in the dry 
season", while a FGD of older men maintained that "Happy people are people who have enough food to eat".

\section{Land}

Land is an important asset in remote communities where, because people make their living from agriculture, the families of those who do not have sufficient, or any land face many difficulties. One participant from a FGD of Southern males aged over 60 years stated, "People that do not own land have to spend money on renting it, therefore, their families will face hardship because they do not have the production capital". A 63-year-old woman, living in a remote area of Isan described her life as "miserable" because,

I don't own a piece of land. I have to rent land to grow cassava but I don't make a lot of money from selling cassava because its price has dropped. I have to feed myself but I don't have enough money to buy food [...] My life is miserable

Another participant remarked, "The happiest second of my life was when I slit the bark of a rubber tree that I grew on my very first piece of land after years of being a labourer" (SSI with a Southern Muslim aged 75 years).

Some of the Isan study sites were villages where the Thai government had allocated land to the villagers for agriculture and farming. However, the government did not give permanent rights over the land to the villagers (e.g. a title deed), which worried some participants. One stated, "I wish the government would give us all a permanent right over the land, so that we can use the title deed to secure a mortgage to improve our farms" (FGD of male participants aged over 60 years, living in remote areas). Data from the South also suggested that people were worried about the insecurity and instability of life and property. One participant said, "My greatest fear is uncertainty. Now we have a title deed over our land. But what if the government wished to expropriate our land? What would we do?" (SSI with a Southern man aged 47 years).

Participants also wanted support and facilities from the Government to help care for the land they had been allocated; for example, one participant said, "I wish the government would set up an irrigation canal to supply water to the land we have got". 
While land is currently regarded as one of people's most important possessions, because the alternative to holding land is to either rent it, or encourage family members to migrate to work as labourers, its status may be changing as young people gravitate towards white-collar occupations in the towns (see Jobs). The increase in labour migration and shift towards non-agricultural activities can lead to the disintegration of family ties, which may explain why participants explicitly emphasised family relationships as part of well-being.

\section{'Materials for Living' (Convenience Goods)}

Materials for living refers to the modern conveniences that make life easier, for example, consumer goods such as refrigerators and mobile phones, modes of transport such as cars and motorcycles, and public facilities such as well equipped schools (for example, one FGD of older women from remote areas in Isan wished that "our school had modern materials such as computers to teach the students with"). Almost everyone in peri-urban areas had a mobile phone and either owned or aspired to own a pick-up truck. According to the WeD Resources and Needs Questionnaire, people's wealth status was also indicated by possession of a TV set, electric fan, refrigerator, and motorcycle (for example, a young Southern Muslim who worked in a rubber plantation said that having a motorcycle was the best thing in his life at the moment). Families that did not have these goods were labelled as 'poor' and their children often developed an inferiority complex.

Data from this study highlighted not only the growth in materialism, especially among the young, but also linked the desire to have the latest consumer goods with the increase in indebtedness. Of our study sites, only Ma Doi seemed to be able to withstand the trend of materialism and maintain a relatively simple way of life, possibly due to its historical links with the Communist Party of Thailand. Researchers also observed a general tendency to measure happiness by wealth, for example,

A happy man is a wealthy man. We know how happy a man is by counting his material goods such as car, money, gold, and jewellery. These rich people don't have to work hard (59-year-old widow from Isan) 


\section{Debt}

When asked about the worst things in her life, a 63-year-old Isan woman who lived in a remote area highlighted "family debt, which gets bigger everyday". The problem was exacerbated by the death of her husband and lack of support from her children ("our descendants hardly visit us [...] I have no one to turn to"). Similarly, a 62-year-old Isan woman who lived in a remote area said, "family debt is like cancer. It causes nervous breakdown. I cry myself to sleep at nights. I can afford to pay only the interest to the creditors, not the principal of the loan". The problem of debt was also evident in the South, albeit to a slighter lesser extent, for example, a 31-year-old Southern Buddhist man said, "The worst moment in my life was when I was addicted to gambling. I lost a lot of money. I made a lot of debt. I troubled my parents".

Debt affected people's mental and physical health (for example, by causing insomnia) as participants worried constantly about repaying their debts. Debt seems to be increasing every day, for example, on average participants from Isan owed between 30,000 and 800,000 Baht. Most of the debt came from mortgages that were invested in farming or other agricultural pursuits; however, some families reported that they had outstanding debt from their children's wedding ceremonies, even though these were celebrated some years before!

I have to repay the debt for my son's wedding that took place four to five years ago. I loaned the money to give a banquet for the wedding and to give a gift to the bride's parents at the engagement ceremony (63-year-old farmer from a remote area of Isan)

Some of the participants had debt from purchasing goods through instalments, which have never been fully paid, for example, a 43-yearold Isan woman who lived in a remote area described the stress that resulted from losing her business (selling gasoline from a barrel), yet still having to repay the loans she had taken to purchase consumer goods:

I have to pay the instalments for a TV set. I don't have the money to pay the monthly payments of my motorcycle. I cannot stretch the money to pay for all my debts. The only thing left for me is my cassava plantation

Each household had many creditors from both governmental and non-governmental agencies. Debt to the government included loans from the village level 'Million Baht Project', the district level 
'Agricultural Marketing Cooperatives', and the 'Bank of Agriculture and Agricultural Cooperatives' (BAAC). Debt from the private sector mostly concerned agricultural essentials such as fertiliser or insecticide that the villagers usually bought from stores with which they had been affiliated for a long time. Normally, villagers would take the goods first, and then repay the debt after they sold their produce. However, in years where there was too little or too much rain, the villagers were not able to repay the debt. Villagers would solve this problem by borrowing money from one creditor to pay another, causing their interest to increase daily. When interview respondents were asked about their hopes for the future, many responded, "I wish my debts were all gone", but none reported any plans for clearing their debts.

FGD data from older Southern men suggests that extravagance and carelessness with money meets with general disapproval:

Families should spend money carefully. They have to plan for their expenses, so that their lives will be good. People should not spend more money than they can earn. They should not spend money on excesses such as buying a cellular phone when they do not have a business to run

This was echoed by an FGD of younger Southern women who said that,

A good woman should not waste money on extravagances. She should be careful with her expenses. She should not have debt. She should not be lazy so that she can make enough money to spend on her family, meaning that there will be no arguments in her family

However, despite the critical attitude to extravagance and debt illustrated above, and the way respondents linked debt to unhappiness, most still claimed that they needed more material goods to make their lives easier. TV sets and motorcycles were particularly identified as indicators of wealth and good QoL. For example, people in periurban areas who could receive signals for mobile phones indicated that these were 'necessities'.

The findings of this study suggest that most of the participants from the South were not as affected by debt as the participants from Isan. One factor may be the Islamic teaching of 'Ayahay' (Koran 4:29), which forbids the charging or paying of interest in transactions between individuals, although this does not affect the practices of commercial banks in the South. 
Respondents commented that currently poor people face more difficulties in life than before because they have no one to turn to. Data from FGDs with participants in the peri-urban areas of Isan indicated that in the past, someone who did not have food to eat could ask for food from a Buddhist temple; now leftover food is sold for people to feed to their cattle or livestock.

The findings of this study suggest that participants have not been influenced by the anti-materialist concept of a 'Sufficiency Economy,' which was put forward by His Majesty King Rama IX and adopted in the 9th development plan for Thailand. The philosophy of the sufficiency economy uses the Buddhist concept of the 'middle way' as the organising principle to govern conduct and ways of living at individual, family, and community levels. It also emphasises developing people's abilities and potential for cooperation so that the nation can develop in line with the forces of globalisation, but is shielded against the inevitable shocks and excesses. The focus on selfdevelopment as the gateway to national development ('explode from within'; 'one for all and all for one') echoes forms of participatory development tried on a smaller scale in other countries. However, it comes with a distinctly Buddhist overlay that suggests a progressive path through self-knowledge, self-control, self-reliance, and selfadjustment, culminating in self-sufficiency ('having enough for a living').

\section{Spirituality and Religion}

Spirituality and Religion not only refers to religious practice, but also incorporates individual spirituality, virtue (ethics), and the psychological dimensions of religion. For example, characteristics of a household that lives well include "generosity to others" (FGD of young Southern men), "keep[ing] virtue in their spirit" (FGD of middle-aged Southern men), and "unity" (FGD of old Southern men and middle-aged Southern women), all of which contribute to good relationships between Buddhists and Muslims.

Families should strongly hold on to truth and merit. Families should admonish their descendants to do good things such as playing sports and stay away from all the temptations and drugs (FGD of males aged over 60 years, living in remote areas in the South) 
The importance of unity in the family extends to the community; for example, one participant said "Everyone should listen when someone else speaks. There should not be any arguments among us." (FGD of older women, living in remote areas of Isan). Arguments or disagreements are not considered appropriate in Isan society because they may cause disturbance among the people. People are ready to compromise and believe that when someone disagrees, they should keep it to themselves in order to be 'polite and nice' to others.

Sometimes specific kinds of virtuous behaviour are expected from men and women. For example,

Good women should be unselfish, sacrificial, and helpful to others (FGD of Southern males aged $18-30$ years)

Good men are those who work for a living, those who take care of their family. It is okay for men to have mistresses or drink occasionally. The bottom line is he must not leave his family or divorce his wife (FGD of men from Isan aged over 60 years)

Some women described limitations in their lives resulting from religious beliefs and practices; for example, a 28-year-old Muslim woman said,

My husband does not have time for his family. He works for Allah. He is too strict [...] The happiest moment in my life was when I was studying in a vocational school. My parents granted me freedom. They were not very serious Muslims. The worst moment in my life was when I had to drop out of college while I was pursuing a bachelor degree. My husband wanted me to quit school to become a housewife. I don't have my own income. I have to depend on the family income. I wish I had a business so that I could make some money

These were not experienced by men who consequently maintained a more positive perspective on religion, for example, a 75-year-old Southern male said,

The best thing in life is to be born into Islam, a great source of strength to stay alive [...] The happiest moment in my life was when I made a journey to attend the Hajj (pilgrimage to Mecca)

It was noted that when asked about 'the most admirable persons in the community', the most frequently identified persons were either related to religion or local government, for example, "the most admirable persons are the Black hermit (a Buddhist monk), Buddhist supporters, and Mr. Jian (member of a provincial council)" (FGD of Isan women aged over 60 years). Southern Muslims also responded "the most admirable persons are the government officials and Imams". 


\section{Education}

Education primarily referred to training to improve occupational skills; it did not seem to be considered intrinsically important and was rarely mentioned in comparison to the areas of family, income, and debt. Some participants believed that the primary education provided by the government was sufficient and felt that that higher education was not necessary for their descendents because they all had to return to the rice fields when they finished school. However, others recognised the importance of education, both for their children and themselves, for example

The bad thing for me was that I had to leave school 10 years ago because the economy was tough. I had to quit school to work (SSI with Southern Muslim man, aged 30 years)

I think low education has a negative impact on people's QoL. Good opportunities, jobs, and salaries are not for the poorly educated like me (24-year-old labourer from Isan)

The happiest moment in my life was when my daughter received her bachelor degree in nursing 3 years ago. Even though I still have to pay the debt for my child's education, I am happy that my daughter has a good job and salary (61-year-old woman from Isan who had a small grocery store)

Although some Thai Muslims received their education from religious schools such as Po-Noh (an Islamic religious teaching institute), the graduates from these schools do not have the completion certificate normally required when people apply for jobs in Thailand. These students, therefore, often became unemployed after graduation and had to migrate to Muslim countries.

Participants also thought that the standard of the government schools was low and described the quality of the school system as fundamentally poor, especially in remote areas. For example, a FGD of young women from the South said "Every community must have a good school and a library for the youngsters [with] devoted teachers who are serious about teaching, knowledge, and discipline".

\section{Other Areas}

Other areas included Infrastructure and Services, for example, one FGD of women aged over 60 years from remote areas of Isan said "I want our village to have good roads that are not bumpy" and 
another described the characteristics of the ideal village as "adequate water supply, reliable electricity, and good road".

Young adult participants perceived Appearance as important, for example, a man who lives well is one who "dresses well and appropriately" (FGD of Southern participants, aged 18-30 years) and "has a good wife [...] a wife with good manners, a wife who does not curse her husband" (FGD of Southern males, aged 31-60 years). Similarly, for middle-aged Buddhist women a happy woman was a "goodlooking woman who dresses nicely [...] a woman who has everything [such as] jewellery and cars" (FGD of Southern Buddhist females, aged 31-60 years). Interestingly, this view was not shared by Muslim women of a similar age who stated that clothes or dresses that merely "look all right" were suitable to wear (FGD of Southern Muslim females, aged 31-60 years).

Local government was another factor, which shaped people's view of an ideal village. For example, an ideal village would have

A good leader, who is just, virtuous, and creates unity among the villagers. The good leader should make electricity available to both the rich and the poor, build concrete roads to the village, and provide lands for farming to every household, so that our descendents can live in a big house together. The good leader should do as he said he would and should not break the laws (FGD of older women, living in remote areas of Isan)

Areas that were mentioned less frequently included Friends and neighbours, Support from outsiders, Market, Water for farming, and Independence, although this partly depended on the method used as they were mentioned more than twice as often by respondents to interviews rather than focus groups. They may also have been implicitly included in the areas described above.

\section{Ideal Lives}

Many participants felt that life could be improved through practical measures: careful planning, saving money, spending wisely, and limiting family size. However, they also emphasised the importance of personal qualities and ways of relating, for example,

Happy people must do the following: mind their thoughts when they are alone (i.e. not think bad things) and mind their words when they are with others (i.e. not start fights) (FGD of males, aged over 60 years, living in remote areas of Isan) 
Focus group responses to questions about the 'best' or most admirable person in the village, and the characteristics of an ideal village were also illuminating. For example, the qualities valued in an 'ideal' person were helpfulness, generosity, unselfishness, being dedicated to the public and making a contribution to society (possibly through leadership), supporting your family, being knowledgeable and having a good mind, practicing religion, behaving well (for example, not fostering dissent), and not being materialistic. These qualities were echoed on a larger scale in the characteristics of an ideal village, which were primarily cooperative relationships, good leadership, religion and morality, and safety and security, although they also included good infrastructure and environment.

When asked what it means to live well, an older woman from Southern Thailand said,

Happiness is something personal. Only a person would know the meaning of his/her own happiness. People might think one is happy when, in fact, he/she is not happy at all. Therefore, it is difficult to determine what happiness really is (FGD of women aged over 60 from Southern Thailand)

This contrasts with the pragmatic response of a 60 -year-old religious scholar from Northeastern Thailand (Isan),

Human well-being is composed of four factors: having offspring, an entourage, a house, and land (SSI with 60-year-old man from Northeastern Thailand)

He was equally specific about the characteristics of people living badly,

Those who steal, those who rob, those who gamble, those who wander at night, those who drink, those who coerce, those who live from hand to mouth, those who are labourers, and those who grow rice just to have enough money to buy rice (ibid)

Further analysis of responses to focus group and semi-structured interview questions about people living well and badly demonstrated considerable overlap between the two concepts in that people who were living well had good family relationships, living conditions, assets and income, employment, health, and religion, while people living badly had the reverse (e.g. unemployment, ill health, etc.). The only difference between the two was the presence of good appearance as an aspect of a good life and debt as indicative of a bad one.

This pattern was repeated with the focus group data on households living well and badly where both sets of responses included family relationships, assets and income, religion, and health, and the 
TABLE III

Summary of PGI scores

\begin{tabular}{lrll}
\hline Category & $N$ & Mean PGI score & SD \\
\hline Thailand & 102 & 52.4 & 21.25 \\
NE Thailand & 54 & 49.3 & 21.54 \\
S Thailand & 48 & 55.9 & 20.58 \\
Rural & 60 & 48.7 & 22.49 \\
Peri-urban & 42 & 57.8 & 18.28 \\
Women & 51 & 49.7 & 19.7 \\
Men & 51 & 55.1 & 22.5 \\
18-30 & 33 & 54.7 & 18.42 \\
31-60 & 35 & 48 & 20.95 \\
60+ & 34 & 54.9 & 23.84 \\
Poor (S Thailand only) & 23 & 49.7 & 22.49 \\
Rich (S Thailand only) & 24 & 57.8 & 18.28 \\
Illiterate & 14 & 49.9 & 30.42 \\
Primary & 39 & 52.1 & 20.44 \\
Secondary & 36 & 51.4 & 20.18 \\
FE/HE & 10 & 63.3 & 12.14 \\
Buddhist & 79 & 51.3 & 21.56 \\
Muslim & 23 & 56.2 & 20.13 \\
\hline
\end{tabular}

only differences were good housing for households that were living well, and lack of employment or land for those that were living badly.

\section{FINDINGS FROM THE PERSON GENERATED INDEX}

While there are some interesting differences in the PGI scores, which move in the expected direction for studies of QoL in Western European populations [e.g. lower scores for people aged 31-60 (Inglehardt, 1990; Frey and Stutzer, 2002) ${ }^{1}$ ], the small size of the subsamples and large standard deviations mean that none of them are significant (see Table III).

Location (rural versus peri-urban), wealth status (poor versus rich), and participation in further or higher education also had a visible effect (there was little difference between the other educational levels), though these may be highly correlated. The difference between the scores of Buddhists and Muslims can be explained by the predominance of Buddhists in the poorer North East as Buddhists living 
in the South score as highly as Muslims (55.68 (SD 21.39) vs. 56.23 (SD 20.13)).

Overall, the most important areas were financial security (mentioned by $90 \%$ of respondents), accommodation (70\%), family relationships $(58 \%)$, health $(53 \%)$, and occupation (49\%), followed closely by children (47\%). Although there are some interesting variations in the areas nominated according to gender, age group, location (rural or peri-urban), and region (South or NE), again the size of the sample limits the conclusions that can be drawn.

Accommodation is more important in the South (possibly due to the insecurity of land tenure), while money and assets are more important in the NE (possibly related to high levels of debt). The population in the South also has a younger age profile (hence the importance of children) and are more likely to be employed than working as farmers, which may be reflected in the priority given to these areas. Surprisingly, there is little difference between respondents from rural and peri-urban areas (in contrast to the interview data), aside from the slightly greater priority given to money/assets, accommodation, and health, which may be more important for an agricultural occupation (see Table IV).

The priorities of male and female respondents are also fairly similar, although health (linked to working capacity) was a lower priority for women, and children were less important for men. Interestingly, family relationships are the top priority for young people, followed by employment, which is a much lower priority for middle-aged and older respondents. Children are more important for people in these groups, but financial security is the top priority. Nonetheless, the priority areas for all groups appear to be the same: financial security, family relationships and children, accommodation, and health, in roughly that order (see Table IV)

\section{SUMMARY OF RESULTS}

This section begins with a narrative summary of the results, before discussing a summary table with a content analysis of all the data ordered according to frequency into 26 areas of QoL (see Table V).

The main area for most respondents was Family Relationships, which included following social norms and codes of conduct, 


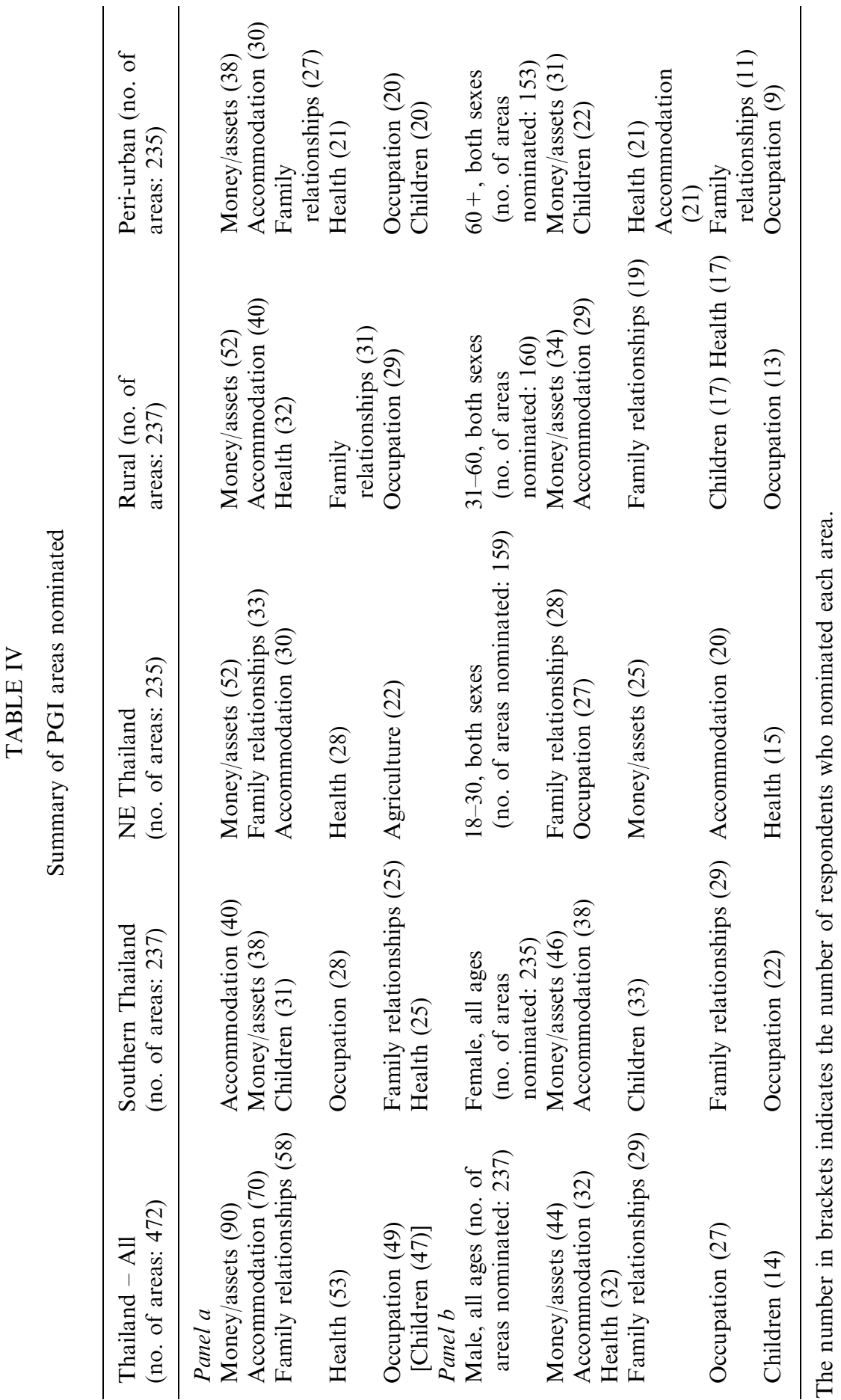




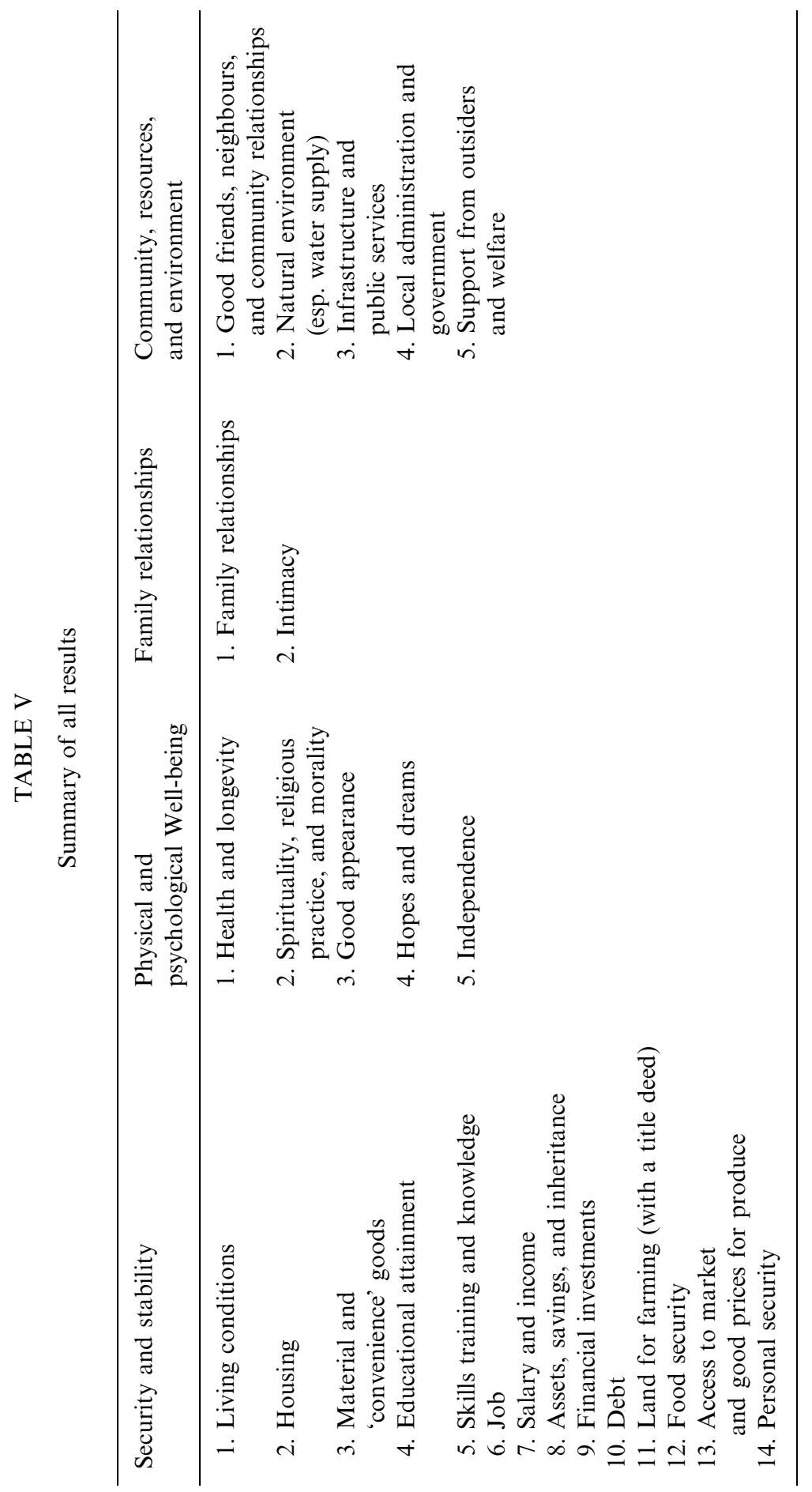


engaging in reciprocal relationships of caring and support (for example, parent and child or husband and wife), and meeting your family's needs. The latter was often a source of stress and conflict, particularly where wives felt husbands neglected their families in favour of alcohol (NE Thailand) or religious observance (Southern Muslims), or parents felt their children weren't showing them due gratitude ('katanyu') because they weren't sending them remittances.

Money was linked directly to well-being, and opportunities for rest, and lack of it was a problem for all age groups: the young who couldn't afford 'positional goods', the middle-aged who couldn't fulfil their family responsibilities, and the old who couldn't afford to stop work. Your Occupation (and that of your children) was a source of money, status, and stress; for example, the young man who thought his girlfriend would leave him if he lost his job in a department store. Owning your own House was a universal goal, although only people in peri-urban areas were concerned about its appearance and size.

People were also concerned about their Health, largely due to the inconvenience and cost of illness, and aware of the psychological impact of stress caused by family problems, isolation of elderly relatives, and debt or insecure land tenure. Respondents to focus groups in the South discussed community health but this was more about the moral implications of substance abuse than the physical. Food insecurity appeared to be only a memory of the elderly and food was primarily discussed in terms of celebration. Land was also a source of pride (one man recalled the day he tapped his first rubber tree on his own plantation) and stress, where people had insecure tenure (usually in the South).

Another common goal was the acquisition of Material or 'convenience goods'; mobile phones were ubiquitous in peri-urban areas, and those who had motorbikes aspired to own pick-up trucks. These goods were a symbol not just of wealth but happiness: "we know how happy a man is by counting his material goods' (59-yearold woman from Isan), which partially explains the continued rise in demand despite rising debts (averaging 30,000-800,000 Baht per household). Although people gave normative accounts of the importance of restraint and financial planning, few seemed to subscribe to the royal vision of the Sufficiency Economy. 
Religious and ethical beliefs and practices were an important part of people's lives, however, most strongly expressed in descriptions of the ideal person (usually a religious or local leader), which focused on their personal characteristics and behaviour towards others. Similarly, while good infrastructure and environment were part of the 'ideal village', good relationships between villagers, good leadership, religious observance and morality, and safety and security were equally important. Education was occasionally mentioned, but usually defined as training to improve one's occupational skills, and not considered intrinsically important. There is a contradiction here, however, in that though people said that the govt. education provided to age 13/14 was sufficient (despite its poor quality), they still took pride in the educational achievements of their children and were prepared to spend considerable amounts of money supporting them through college or the religious schooling system in the South.

The results of the content analysis of data from focus groups, semi-structured interviews, the PGI, and field notes from observation and participant observation were ordered according to frequency into 26 areas of QoL, which were then grouped under the headings in Table V.

The top five areas for all respondents to focus groups, semistructured interviews, and the PGI were:

1. Family relations (area mentioned 757 times)

2. Health (307)

3. Money and assets (271)

4. Occupation (238)

5. Accommodation (184)

These closely parallel the responses to focus group and interview questions about households/ individuals living well or badly, however, interestingly neither Spirituality and religion nor Good appearance is mentioned. Food, Debt, and Land were also omitted from the top five, although these were relatively frequently referred to in interviews and focus group discussions (n.b. Debt appeared predominantly in the North East and Land in the South). Additionally, some areas were rarely mentioned in the PGI, but frequently referred to in semi-structured interviews and focus group discussions, for example, Spirituality and religion and Debt. 


\section{GENERAL CONCLUSIONS}

The categories derived by WeD-Thailand resemble those from previous qualitative studies in Thailand (see Table VI), however, in all cases the $\mathrm{WeD}$ categories are more fully developed, for example, 'house' expands to include 'material and 'convenience' goods 'having money' also includes being free from debt, and 'good spouse' becomes having an intimate relationship with your partner.

The WeD-Thailand categories also overlap with the facets of international QoL measures (see Table VII), especially the satisfaction measure used by Biswas-Diener and Diener (2001) in the slums of Calcutta, which is the only measure to mention 'morality' and 'romantic [relationships]'. Where the Thai data differs is the level of detail, which makes the facets visibly relevant and easier to respond to; for example, debt and having convenience goods are important in their own right and carry meanings that extend beyond the material.

'Hopes and dreams' are not included in the other measures (the International Well-being Index (IWI) mentions 'future security' but this refers to economic expectations), nor is 'Independence', except in so far as it relates to 'self-esteem' (WHOQOL) or 'what you achieve in life' (IWI). There is also a cluster of facets on natural resources, infrastructure and services, local government, and support/welfare provided by external bodies, which are not included in the other indices and only alluded to in the WHOQOL's 'physical environment'. This is probably the key difference between the Thai categories and the international facets, which seem to assume a stable natural environment, sufficient public goods and services, good governance, and a social security system, and then ask about the aspects of QoL that remain. Clearly 'positive feelings' and 'friendship' are also important to people to developing countries, but the extent to which they can outweigh, or even exist in the absence of basic services is debatable.

Returning to the top five elements of a good life identified by the study (see p. 18), Family Relationships, Occupation, and Accommodation overlap with the top five 'necessities for a good life' endorsed by members of the enlarged European Union (EU-25) (Delhey, 2004). The differences in the choice of priorities are the EU-25's inclusion of a 'good education' and 'sufficient leisure time', which also received a lower endorsement from the 13 new members of the EU 


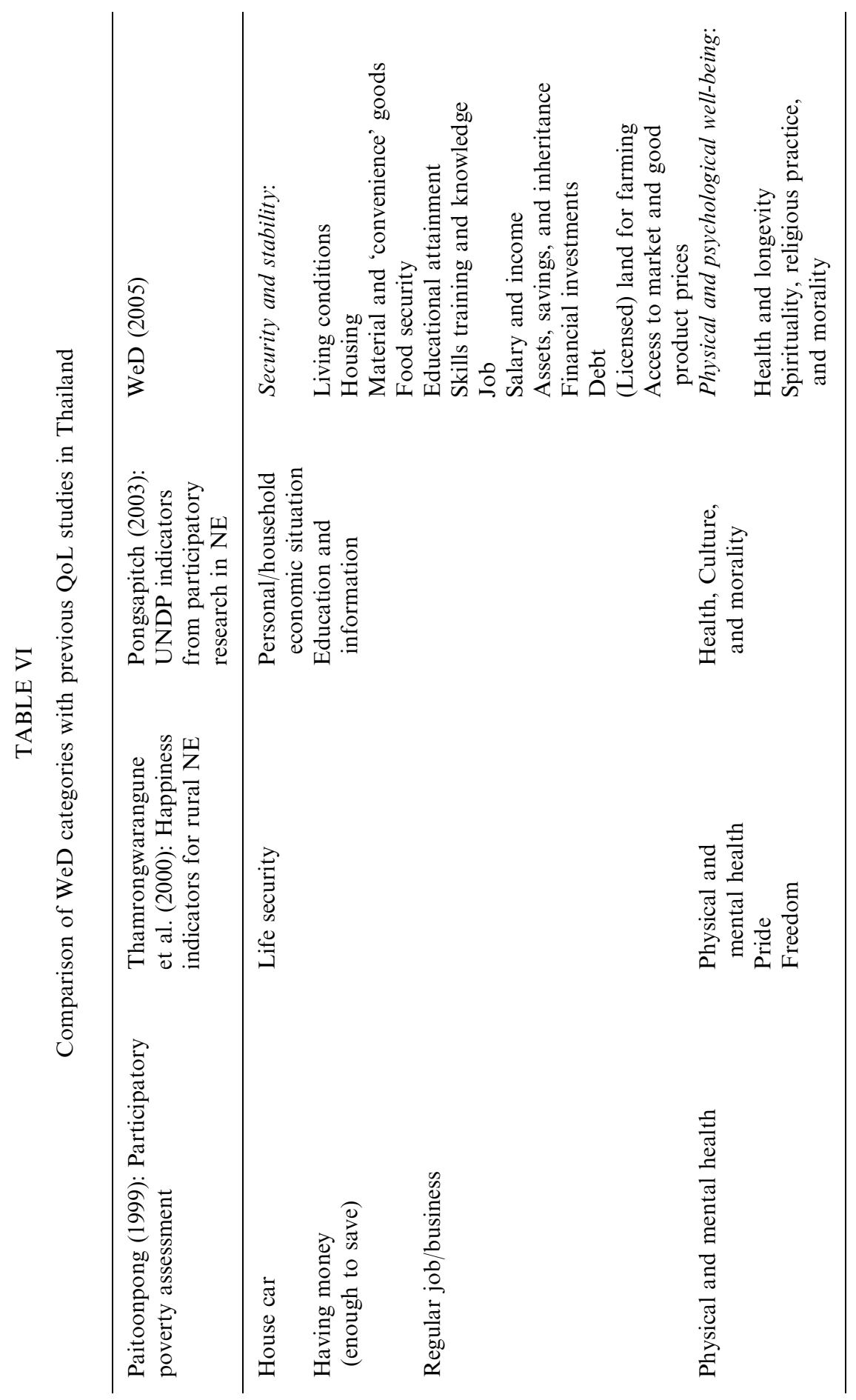




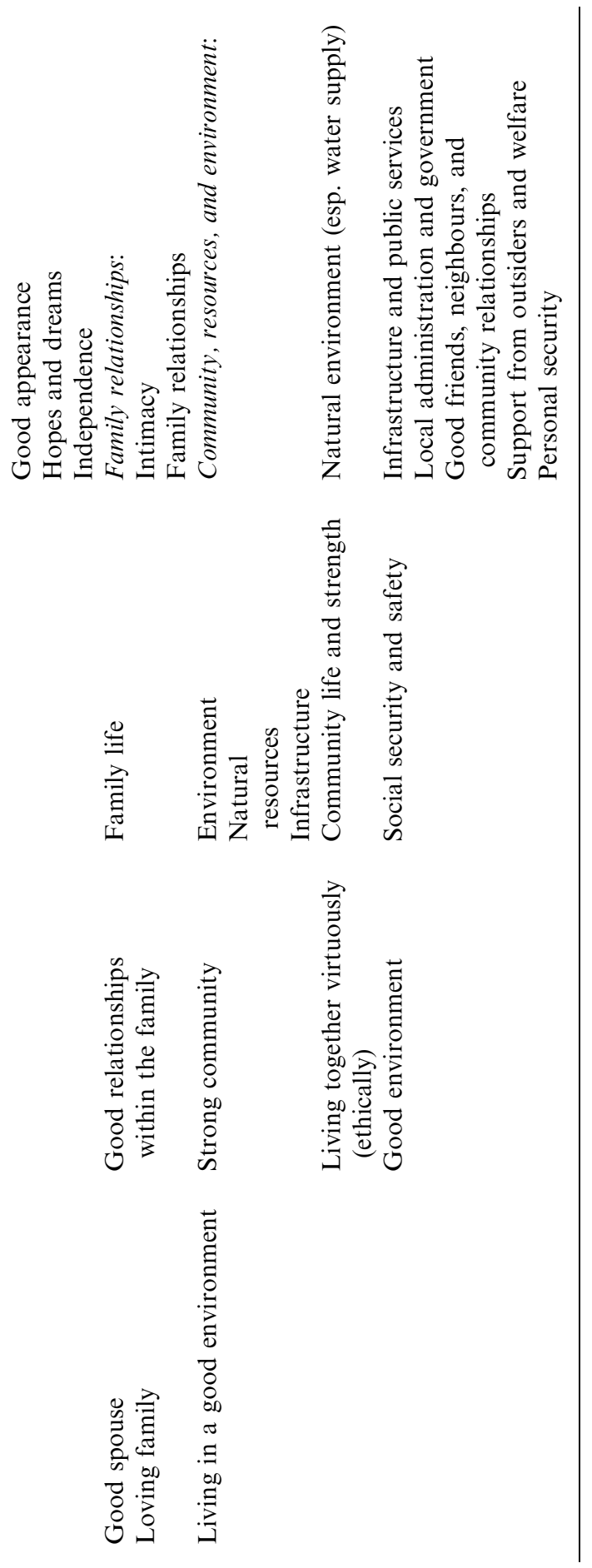




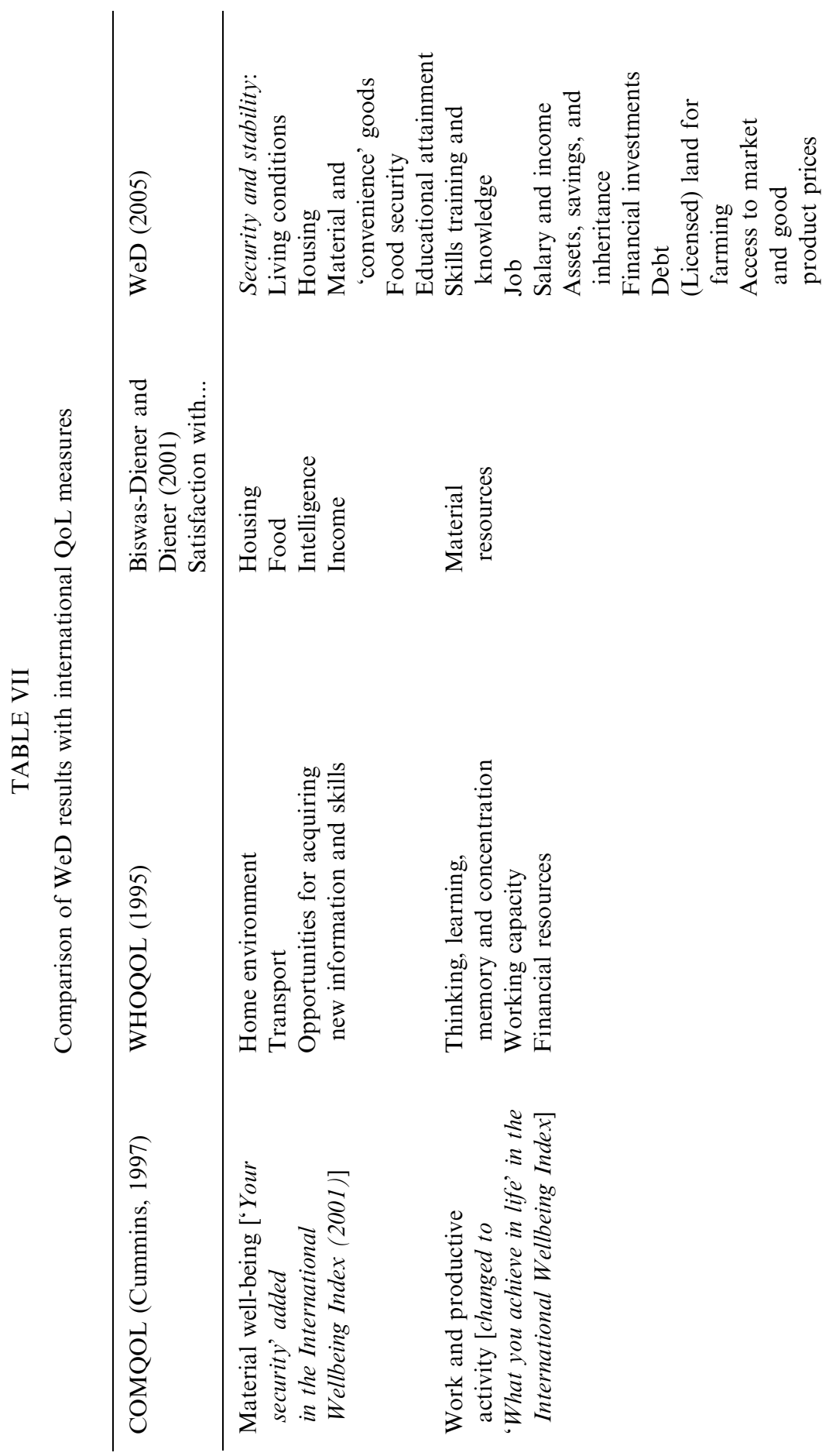


$\ddot{0}$

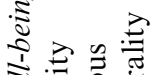

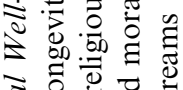

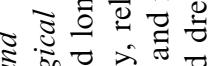

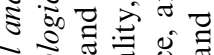

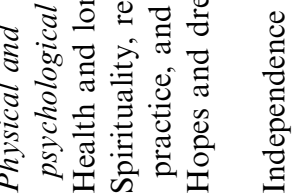

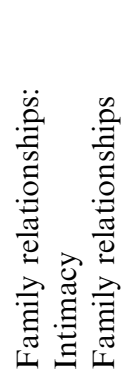

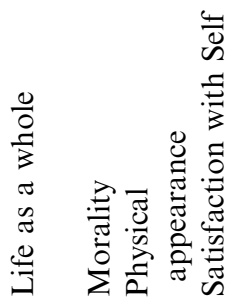

-

䒿

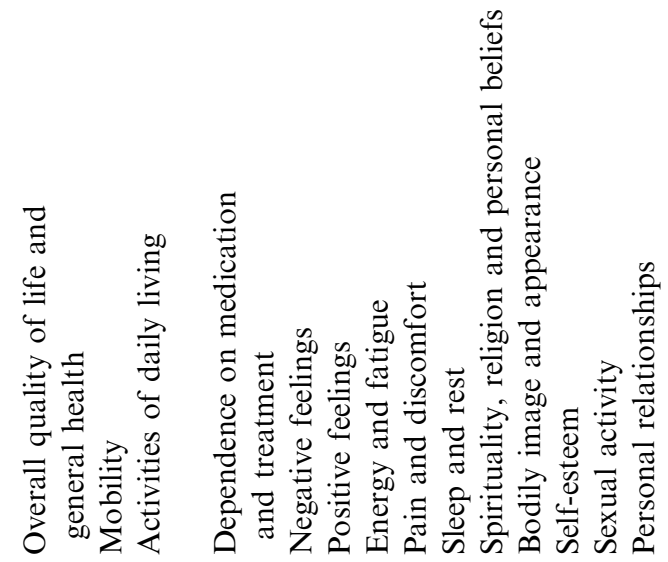
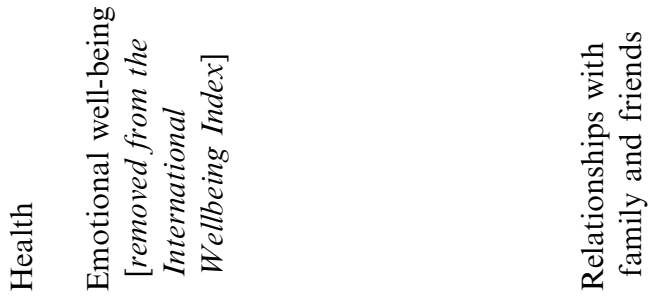


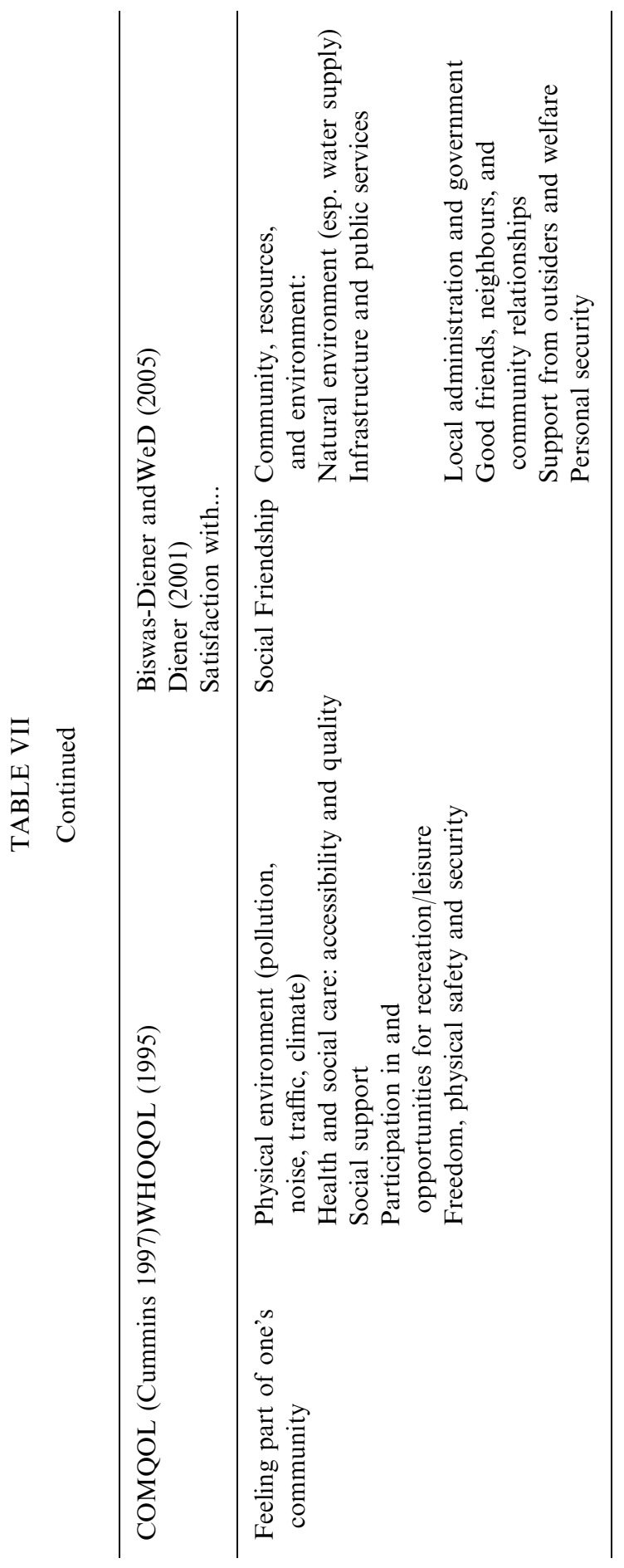


(mainly lower-income countries). The Thai respondents prioritised 'money and assets' and 'health' instead (closely related to occupation and income), but the importance of these items can't be compared as they were not included as options in the European survey. The EU-25 also included 'being useful to others', which was important to the Thai respondents (forming part of the definition of an 'ideal' person) but not one of their main priorities.

In conclusion, the study raises a number of interesting questions: firstly, do the Thai respondent's reports on the sources of their wellbeing justify a different approach to well-being in LDCs?; secondly, does they support theories of the universality of human needs?; and thirdly, to what extent can this sort of exercise be used to guide policy?

The answer to the first question is that while the priorities of people in Thailand are not very different to those of people in the rest of the world, they are not necessarily reflected in international quality of life measures, which seem to lack a material base at the societal level. Additionally, adapting a generic QoL measure without including items that are specific not only to Thailand, but to the areas of Thailand that the project is working in (for example, insecurity of land tenure or debt) would miss many of the local people's most important preoccupations.

Second, although the main priorities of the Thai respondents clearly overlap with theories of human need (for example, Doyal and Gough (1991) class physical health as a 'basic need' and 'significant primary relationships', 'adequate protective housing', and 'economic security' as intermediate needs, and Ryan and Deci (2001) characterise 'relatedness' and 'competence' (expressed through 'occupation') as fundamental psychological needs); there are other, more subtle indicators of well-being that shouldn't be neglected (for example, being able to live a moral life, knowing your land can't be taken away from you, and having hopes and dreams).

While this data should provide some reassurance to policy makers since it recognises the importance of improvements in public goods and services, access to markets, and the ability to consume and invest, the differences in priorities it identifies challenges 'one-size fits all' policies. It also asserts that material gains should not come at the expense of family and community relationships, or adherence to religious and moral codes. The responses suggest that development 
can only occur in a stable environment, characterized by financial stability, personal security, good governance, and some form of welfare safety net. But although this was a relatively participatory exercise, people's responses do not provide unequivocal policy recommendations and need to be read in the context of other data. For example, the lack of discursive attention to education is contradicted by the behaviour of people in these regions - young people in the NE migrating to Bangkok for training and Muslim parents supporting a fee-paying system of religious schools in the South. The value of this type of data may be more apparent over the long-term as it feeds into a body of research that attempts both to change the priorities of policy makers and provide more accurate measures for assessing their success or failure.

\section{NOTES}

1 But see Graham and Sukhnatar (2004) who observed a substantial increase in the low point on the standard U-shaped age and happiness curve in Latin America and Russia.

\section{REFERENCES}

Anderson, K.L.: 1999, 'Conceptualization and measurement of QoL as an outcome variable for health care intervention and research', Journal of Advanced Nursing 29, pp. 298-306.

Ayawut, D. and A. Phitakham: 2004, Quality of Life of People in Northeastern Thailand. Unpublished manuscript.

BBC. Religious \& Ethics: Islam. http://www.bbc.co.uk/religion/religions/islam/ index.shtml. Accessed: December, 2004.

Camfield, L. Conducting Research into QoL in Thailand. WeD Presentation At Khon Kaen Thailand, October 2004.

Dalai Lama, H.H. and H.C. Cutler: 1999, The Art of Happiness (Loronet Hodder \& Stoughton, Great Britain).

Delhey, J.: 2004, Life Satisfaction in an Enlarged Europe (Office for Official Publications of the European Communties, Luxembourg).

Doyal, L. and I. Gough: 1991, A Theory of Human Need (Macmillan, London).

Field, P.A. and J.M. Morse: 1985, Nursing Research: the Application of Qualitative Approach (Chapman \& Hall, London).

Fielding, N.: 1993, Ethnography, in N. Gilbert (ed.), Researching Social Life (SAGE Publications, California).

Graham, C. and A. Sukhtankar: 2004, 'Does economic crisis reduce support for markets and democracy in Latin America? Some evidence from surveys of public opinion and wellbeing', Journal of Latin American Studies 36, pp. 349-377. 
His Majesty King Rama IX. New Paradigm. http://www.swu.ac.th/royal/book4/ b4c1.html. Accessed: December, 2004.

Katschnig, H.: 1997, 'How useful is the concept of QoL in psychiatry?', Current Opinion in Psychiatry 10, pp. 337-345.

Lincoln, Y.S. and E.G. Guba: 1985, Naturalistic Inquiry (Sage, Beverley Hills).

Macduff, C.: 2000, 'Respondent-generated QoL measures: Useful tools for nursing or more fool's gold?', Journal of Advanced Nursing 32, pp. 375-382.

Ministry of Public Health: 1986, Basic Needs and Development (War Veteran Welfare Press, Bangkok) (in Thai).

National Economic and Social Development Plan, 2002-2006: 2002 (Office of the Prime Minister, Bangkok).

National Economic and Social Development Board. http://www.nesdb.go.th. (Accessed: December, 2004)

Pongsapitch, A.: 2000, 'QoL of Thai People', in Proceedings in Nursing, Conference on QoL Research (Chulalongkorn University, Bangkok) (in Thai).

Pongsapitch, A.: 2000, Wellbeing Measurement Tool Development of Thai People (Social Research Institute, Chulalongkorn University and The Thailand Research Fund, Bangkok) (in Thai).

Press release: 2004, Report of Alcohol Consumption in 2004 (Ministry of Public Health Thailand, Bangkok).

Puangsamlee A. and A. Ajaum (eds.): 2000, Wellbeing Measurement Tool Development of Thai People and Thai Society (The Thailand Research Fund, Bangkok) (in Thai).

Ruta, D.A., A.M. Garratt and M. Leng: 1994, 'A new approach to the measurement of QoL: The Patient-Generated Index (PGI)', Med Care 32, pp. 1109-1126.

Ryan, R.M. and E. Deci: 2001, 'Self-determination theory and the facilitation on intrinsic motivation social development and well-being', American Psychologist 55, pp. 68-78.

Skevington, S.M.: 2003, QoL in Poverty: From Health-related Quality of Life. Bath, UK: Well-being in Developing Countries Research Group and WHO Centre for the Study of Quality of Life.

Thairath Daily News: December, 13; 2004, 55 (17128): 1 (in Thai).

Thamrongwarangune, A.: 2000, Wellbeing Measurement Tool Development of Thai People (The Thailand Research Fund, Bangkok) (in Thai).

World Health Organisation: 1991, World Health Statistics Annual Report (WHO, Geneva).

Wellbeing in Developing Countries

Laura Camfield

ESRC Research Group (WeD)

University of Bath

3E 2.10

Bath

Banes, BA2 7AY

UK

E-mail: l.camfield@bath.ac.uk 